\title{
Comparison of methods for high quantity and quality genomic DNA extraction from raw cow milk
}

\author{
T. Usman*, Y. Yu*, C. Liu, Z. Fan and Y. Wang
}

Key Laboratory of Agricultural Animal Genetics, Breeding and Reprodution, Ministry of Agriculture, National Engineering Laboratory Animal Breeding, College of Animal Science and Technology, China Agricultural University, Beijing, China

*These authors contributed equally to this study Corresponding author: Y. Wang

E-mail: wangyachun@cau.edu.cn

Genet. Mol. Res. 13 (2): 3319-3328 (2014)

Received January 28, 2013

Accepted July 4, 2013

Published April 29, 2014

DOI http://dx.doi.org/10.4238/2014.April.29.10

\begin{abstract}
Isolation of sufficient quantities of high quality DNA is a prerequisite for molecular studies. Milk somatic cells can be used; however, inhibitors such as fats and proteins make milk a difficult medium for extracting large amounts of quality DNA. We optimized, evaluated and compared three methods, Modified Nucleospin Blood Kit method, Modified TianGen Kit method and Phenol-Chloroform method for genomic DNA extraction from bovine milk. Individual cows' milk and bulk milk samples were collected from a China agricultural university dairy farm. Genomic DNA extracted from each milk sample by the three methods was evaluated for quantity and purity by spectrophotometry and gel electrophoresis, as well as PCR and sequencing. All the three methods were found suitable for genomic DNA isolation from bovine milk, PCR applications, and sequencing. Comparing the three methods, we found that the Modified Nucleospin Blood Kit method was significantly better than the Phenol-Chloroform method in terms of quantity as well as quality (amount, concentration, 260/280nm and 260/230nm absorbance ratio),
\end{abstract}


whereas, the Modified TianGen Kit method was more efficient than the Phenol-Chloroform method and cheaper than the Modified Nucleospine Blood Kit method; it yielded reasonably good quantities of good quality DNA and would be suitable for large-scale genotyping of lactating cows.

Key words: Bovine milk; Genomic DNA extraction method; High quantity and quality DNA; PCR; PCR-sequencing

\section{INTRODUCTION}

The isolation of high quality and quantity genomic DNA is prerequisite for mammalian molecular studies such as DNA sequencing, SNP identifications, paternity testing, etc. (D'Angelo et al., 2007; Agbagwa et al., 2012). In cattle, genomic DNA is normally extracted from peripheral blood leukocytes, different tissues or hair follicles. Although milk is animal friendly and a routine source in the dairy industry (D'Angelo et al., 2007), inhibitors in milk such as fats and proteins render it difficult source for extracting high quantity and quality DNA (Lipkin et al., 1993; Amills et al., 1997; Murphy et al., 2002; Feligini et al., 2005; Cremonesi et al., 2006). To date, different commercial kits for improved DNA extraction are available for many kinds of tissues except for milk (Biase et al., 2002; Studer et al., 2008; O'Grady et al., 2008; Gao et al., 2011).

Somatic cells are normal components of milk. In healthy quarters of dairy cows, somatic cell count (SCC) per milliliter milk ranges from $2 \times 10^{4}$ to $2 \times 10^{5}$ cells. In an infected quarter, SCC ranges from $3 \times 10^{5}$ to $9 \times 10^{7}$ cells $/ \mathrm{mL}$ milk (Holmes and Wilson, 1984; Kehrli Jr and Schuster, 1994). As SCC is strongly correlated with mastitis incidence $\left(r_{g}=0.84\right.$, Hinrichs et al., 2005), lower SCC or log-transformed SCC (somatic cell score, SCS) is an indicator for selecting individuals with mastitis resistance in dairy populations (Pant et al., 2007). Thus, milk is a useful source for extracting genomic DNA that shows its large-scale use not only for mastitis resistance study but also for public health investigations.

To improve the isolation of high quantity and quality genomic DNA from bovine milk, the present study optimized, evaluated and compared three DNA extraction methods: modified Nucleospin Blood kit, modified TianGen kit and classic phenol-chloroform methods. The downstream application and genotyping confirmation using the isolated genomic DNA were also performed and discussed.

\section{MATERIAL AND METHODS}

\section{Samples}

The milk samples were collected from six lactating Holstein cows and bulk milk (seven biological repeats) in the China Agricultural University dairy farm. All cows were fed the same lactation diet according to energy recommendations for lactating Chinese Holstein cows. The animals were in their 2nd and 3rd parities and their somatic cell counts per milliliter milk ranged from $1.2 \times 10^{5}$ to $4.4 \times 10^{5}$. Animals were milked twice a day and the milk samples were collected at evening milking from each cow. Fifteen repeat samples were collected from each cow and bulk milk, thus, a total of 105 milk samples were collected (Figure 1). Five 
repeat samples from each cow and from the bulk milk were employed for each of the three methods used in the study (35 milk samples per method). Fifty milliliters milk for each sample was collected in tubes under aseptic conditions and immediately transferred in ice boxes to the laboratory. The milk samples were then stored at $-20^{\circ} \mathrm{C}$ for later use.

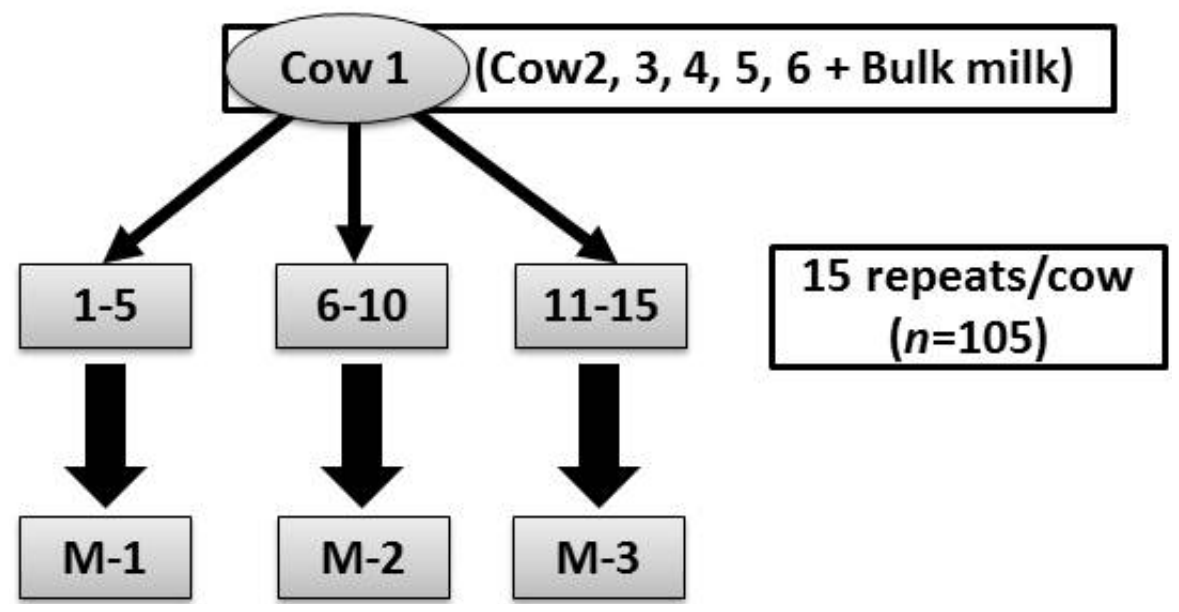

Figure 1. Bovine milk samples collection per biological repeat and allotment to each of the DNA extraction method.

\section{Methods of DNA extraction}

Three different methods were used for isolation of genomic DNA from the milk samples. Method 1, the modified Nucleospin Blood kit (MACHEREY NAGEL, GmbH \& Co. KG, Germany) method, was the application of the commercial kit with a few modifications to eliminate potential PCR inhibitors and increase DNA yield and purity. Method 2, the modified TianGen kit (TIANGEN BIOTECH BEIJING, CO., LTD, China) method, was used for the first time for genomic DNA extraction from bovine milk. The classical phenol-chloroform method (Method 3) was used according to our procedures developed for genomic DNA extraction from bovine milk.

\section{Sample pre-treatment}

The first two pre-treatment steps were common to all the three methods, that is, 50$\mathrm{mL}$ milk samples in tubes were centrifuged at $2000 \mathrm{~g}$ for $20 \mathrm{~min}$ at room temperature and the supernatant was discarded. The somatic cell pellet was resuspended in $20 \mathrm{~mL}$ phosphate-buffered saline (PBS, $\mathrm{pH}$ 7.4) by pipetting well, before centrifugation at $4000 \mathrm{~g}$ for $10 \mathrm{~min}$ at room temperature to dissolve milk casein before the use of proteinase $\mathrm{k}$. The somatic cell pellet was then treated with different buffers according to each method as followed.

\section{Method 1: Modified Nucleospin Blood kit}

The somatic cell pellet was resuspended in $200 \mu \mathrm{L}$ PBS, and DNA was extracted from milk according to manufacturer instructions with the following modifications. Ethanol 
$(100 \%)$ was pre-cooled before use and the final washing step with ethanol containing buffer was repeated. After the final washing step, Nucleospin columns were centrifuged at 11,000 $g$ for $2 \mathrm{~min}$, and the column was then placed in an open-capped 1.5-mL tube for $2 \mathrm{~min}$ to allow the evaporation of the remaining ethanol. Finally, $30 \mu \mathrm{L}$ pre-heated elution buffer (TE) were added to the silica membrane and incubated for $5 \mathrm{~min}$ to allow the DNA to dissolve in TE. After centrifugation at $11,000 \mathrm{~g}$ for $2 \mathrm{~min}$, the eluted DNA was again placed on the silica membrane and centrifuged to ensure that the entire DNA had passed into the $1.5-\mathrm{mL}$ tube.

\section{Method 2: Modified TianGen kit}

The somatic cell pellet was resuspended in $200 \mu \mathrm{L}$ PBS and transferred to a new 1.5$\mathrm{mL}$ tube according to manufacturer instructions with the following modifications incorporated to enhance DNA quality. Pre-cooled absolute ethanol was used in the last washing step. After centrifugation of the empty silica membrane (CB3) tube at 12,000 $\mathrm{g}$ for $2 \mathrm{~min}$, the CB3 tube was put in an open 1.5-mL tube for 5 min to allow the evaporation of the remaining ethanol. A volume of $30 \mu \mathrm{L}$ pre-heated TE was directly applied to the silica membrane and incubated for $10 \mathrm{~min}$ to allow the DNA to dissolve in the TE, followed by centrifugation at 12,000 $\mathrm{g}$ for 2 min. The TE was picked up and again put on the silica membrane and centrifuged to make sure that the entire eluted DNA was filtered.

\section{Method 3: Phenol-chloroform extraction}

Somatic cells pellet was resuspended with $400 \mu \mathrm{L}$ TE and transferred to a new $1.5 \mathrm{~mL}$ tube followed by addition of $30 \mu \mathrm{L}$ proteinase $\mathrm{K}$, the mixture was well mixed and then incubated at $56^{\circ} \mathrm{C}$ for $1 \mathrm{~h}$. Subsequently, equal volume of Phenol-Chloroform was added and the mixture was vigorously rotated for $2 \mathrm{~min}$ followed by centrifugation at $12000 \mathrm{~g}$ for $5 \mathrm{~min}$. The aqueous phase was transferred very carefully, avoiding the protein at the crystal white layer between the phenol-chloroform and the mixture and using a $200-\mu \mathrm{L}$ pipette, to a new $1.5 \mathrm{~mL}$ tube containing $400 \mu \mathrm{L}$ isopropanol and then gently mixed by up and down slow movement. After centrifugation at $12,000 \mathrm{~g}$ for $5 \mathrm{~min}$, the solution was gently discarded using a $200-\mu \mathrm{L}$ pipette, leaving the last $100 \mu \mathrm{L}$ liquid containing DNA. The DNA was washed twice with 1 $\mathrm{mL}$ absolute pre-cooled ethanol with centrifugation at $12.000 \mathrm{~g}$ for $5 \mathrm{~min}$. At last, after gentle removal of the above solution, the $1.5-\mathrm{mL}$ tube was placed upside down on blotting paper to let the DNA dry for 5-10 min. The purified DNA was dissolved in $30 \mu \mathrm{L} \mathrm{dd} \mathrm{H}_{2} \mathrm{O}$.

\section{Spectrophotometer and gel electrophoresis}

After genomic DNA isolation, the quantity and purity of DNA were measured using a NanoDrop ${ }^{\text {TM }}$ ND-2000c Spectrophotometer (Thermo Scientific, Inc.). Protein contamination was measured by the $260 / 280 \mathrm{~nm}$ absorbance ratio, whereas, $260 / 230 \mathrm{~nm}$ was used to determine contamination by reagents. Typical curves produced by all three methods using the NanoDrop spectrophotometer were evaluated. The quantity and integrity of DNA isolated with each method was also evaluated by gel electrophoresis. Three microliter of each DNA extract was analyzed on a $1.5 \%$ agarose gel containing $0.5 \%$ ethidium bromide and the bands visualized by UV illumination. 


\section{Polymerase chain reaction and sequencing of bovine CD4 gene}

The presence of amplifiable DNA was evaluated by polymerase chain reaction (PCR) using the primers for intron 6 of bovine $C D 4$ gene having a length of 735 bp (He et al., 2011):

CD4-F: 5'-CCCCCTCCCAGTTCCTTA-3'

CD4-R: 5'-AGCCTTTCCCTTCCAGTTCT-3'

Amplification reactions were run in a total volume of $20 \mu \mathrm{L}$, and the optimal reaction

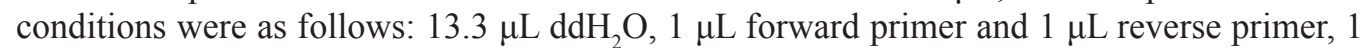
$\mu \mathrm{L}$ dNTPs, $2 \mu \mathrm{L} 10 \mathrm{X}$ buffer, $0.02 \mu \mathrm{L}$ Hifi polymerase and $1.5 \mu \mathrm{L}$ genomic DNA. The PTC200 PCR instrument (Bio-Rad Inc., Hercules CA, USA) was used to carry out PCR. Standard cycling conditions included an initial denaturation step at $95^{\circ} \mathrm{C}(5 \mathrm{~min})$, followed by 35 cycles of denaturation at $95^{\circ} \mathrm{C}(30 \mathrm{~s})$, and annealing at $56^{\circ} \mathrm{C}(30 \mathrm{~s})$, and finally, extension at $72^{\circ} \mathrm{C}(10$ $\mathrm{min})$. The PCR products were analyzed by electrophoresis on a $2 \%$ agarose gel stained with ethidium bromide for visualization.

PCR products of all the three methods for each individual cow and bulk milk were directly used for sequencing (PCR-sequencing). Discovery of SNPs was conducted using the Chromas software, version 2.22, licensed to Technelysium.

\section{Statistical analysis}

The following model was used to evaluate the three different DNA extraction methods by the SAS (9.1) software.

$$
y_{i j}=\mu+p_{i}+e_{i j}
$$

where $y_{i j}=$ DNA score by evaluation criterion for the $j$ th sample of the $i$ th extraction method, $\mu=$ overall mean; $p_{i}=$ effect of $i$ th DNA extraction method $(i=1,2$ and 3$)$; and $e_{i j}=$ random residual.

\section{Computer packages}

Computer packages including M.S. Excel and SAS (SAS Institute Inc., 2002) were used for data handling and analysis.

\section{RESULTS}

\section{Spectrophotometer measurements and gel electrophoresis}

Genomic DNA extraction measurements using the NanoDrop spectrophotometer are shown in Table 1. According to the DNA concentration and amount, the results indicated that using the Modified Nucleospine Blood kit method yielded a significantly higher quantity of genomic DNA compared to the classic phenol-chloroform method $(\mathrm{P}<0.05)$.

Genomic DNA bands by gel electrophoresis showed that the integrated brightest bands were produced by the Modified Nucleospin Blood kit method (lanes 7-9) followed 
by the Modified TianGen kit method (lanes 4-6) and phenol-chloroform method (lanes 1-3) (Figure 2A). The pattern of curves on 260, 280 and $230 \mathrm{~nm}$ showed that the Modified Nucleospin Blood kit method (M1) produced a standard pattern followed by the Modified TianGen kit method (M2) and then by phenol-chloroform method (M3) (Figure 2B). The absorbance ratios of $260 / 280 \mathrm{~nm}$ and $260 / 230 \mathrm{~nm}$ indicated that the genomic DNA quality was significantly better $(\mathrm{P}<0.05)$ with the Modified Nucleospin Blood kit method than the phenol-chloroform method.

Table 1. Comparison of three DNA extraction methods using three spectrophotometer measurements (concentration, 260/280 nm and 260/230 nm), efficiency and cost per sample by each method (cost includes only material).

\begin{tabular}{lcccccc}
\hline DNA extraction method & Concentration $(\mathrm{ng} / \mu \mathrm{L})$ & Amount $(\mathrm{ng})$ & $260 / 280(\mathrm{~nm})$ & $260 / 230(\mathrm{~nm})$ & Time $($ hour$)$ & Cost/sample $(\$)$ \\
\hline Modified Nucleospin Blood Kit & $170.5 \pm 113.9^{\mathrm{a}}$ & $5102 \pm 3469^{\mathrm{a}}$ & $1.85 \pm 0.17^{\mathrm{a}}$ & $1.91 \pm 0.83^{\mathrm{a}}$ & 1.15 & 2.76 \\
Modified TianGen Kit & $139.9 \pm 92.7^{\mathrm{ab}}$ & $4182 \pm 2987^{\mathrm{ab}}$ & $1.75 \pm 0.21^{\mathrm{ab}}$ & $1.21 \pm 1.04^{\mathrm{ab}}$ & 2 & 1.38 \\
Phenol-Chloroform Protocol & $105.9 \pm 55.6^{\mathrm{b}}$ & $3179 \pm 1690^{\mathrm{b}}$ & $1.64 \pm 0.22^{\mathrm{b}}$ & $1.06 \pm 1.19^{\mathrm{b}}$ & 3.15 & 0.77 \\
\hline
\end{tabular}

Values with the same subscript are not statistically different $(\mathrm{P}>0.05)$ from each other but they differ significantly $(\mathrm{P}<0.05)$ from values with different subscript.

A

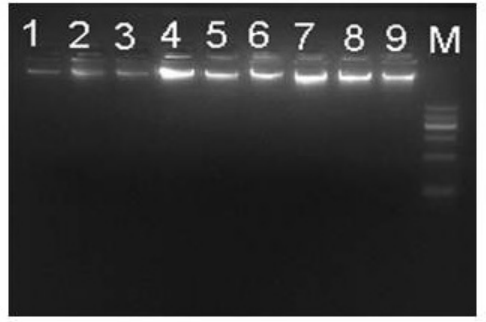

B

M1
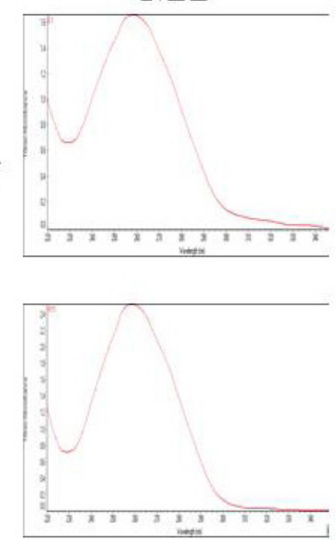

M2
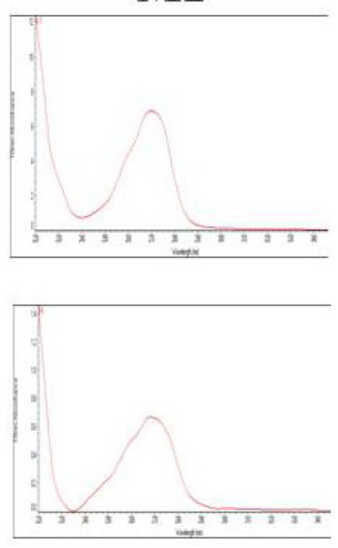

M3
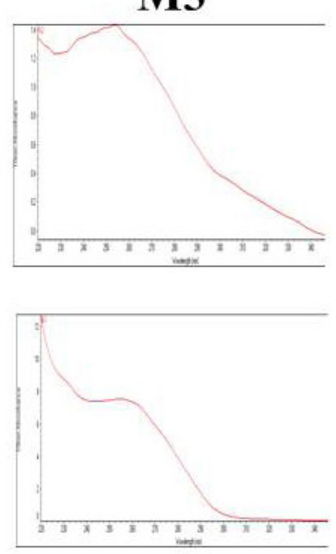

Figure 2. Representative results from gel electrophoresis analysis of genomic DNA and pattern of curves for the three methods. A. Phenol-Chloroform method (lanes 1-3), Modified TianGen Kit method (lanes 4-6), Modified Nucleospin Blood Kit method (lanes 7-9); lane $M=$ molecular weight marker $\lambda$ DNA/HindII digest. B. Lane $M 1=$ Modified Nucleospin Blood Kit method, lane M2 = Modified TianGen Kit method, lane M3 = Phenol-Chloroform method. 


\section{Processing time and cost}

Processing time and cost per sample for each method is also listed in the Table 1 . The results showed that although Modified Nucleospin Blood kit method was a bit expensive but yielded DNA of highest quality and quantity in shortest time amongst the three methods. Phenol-chloroform protocol was the cheapest one but the DNA generated was of average quality and quantity and also took a relatively long time. Amongst the three methods, the Modified TianGen Kit method was efficient than Phenol-Chloroform method and cheaper than Modified Nucleospin Blood kit method and yielded DNA of reasonable quantity and quality.

\section{Polymerase chain reaction}

Polymerase chain reaction (PCR) of the intron 6 of bovine $C D 4$ gene indicated that genomic DNA extracted by all the methods was successfully amplified (Figure 3 ). The brightest bands were with the Modified Nucleospin Blood kit method followed by Modified TianGen kit method and then by phenol-chloroform method (Figure 3A).

A

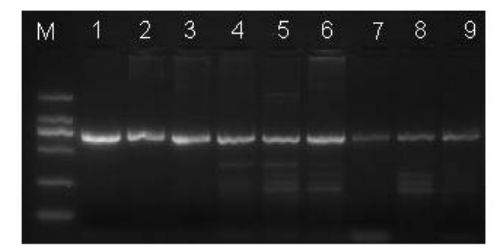

B

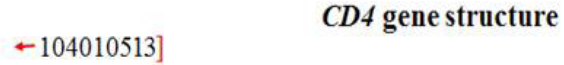

B

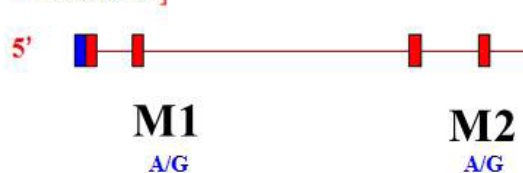

$-103994655]$

C

A/G

A/G

M3

Individual cow
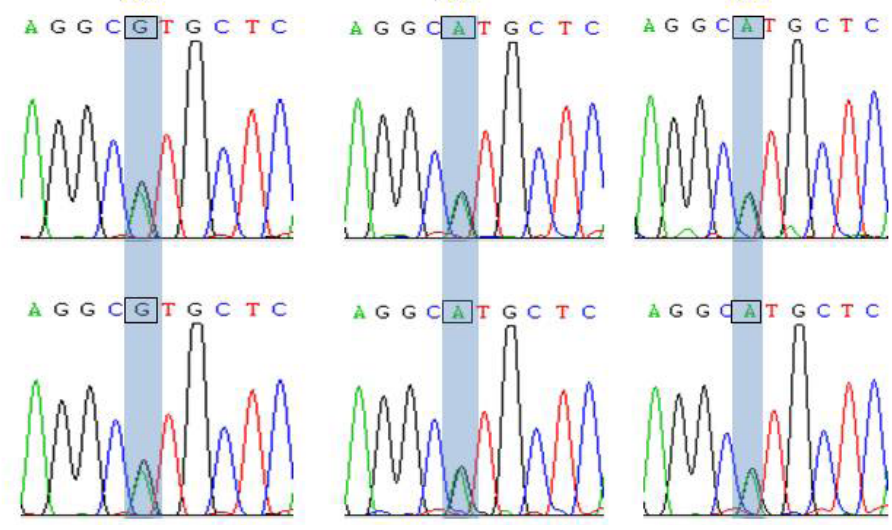

Figure 3. PCR product gel electrophoresis and sequencing results figure. A. Phenol-Chloroform method (lanes 1-3), Modified TianGen Kit method (lanes 4-6), Modified Nucleospin Blood Kit method (lanes 7-9); lane M= molecular weight marker $\lambda$ DNA/HindII digest. B. SNP g.13598C $>$ T in CD4 intron 6 on BTA 5. C. lane M1 = Modified Nucleospin Blood Kit method, lane M2 = Modified TianGen Kit method, lane M3 = Phenol-Chloroform method. 


\section{PCR-sequencing}

The PCR product of the bovine $C D 4$ intron 6 was directly sequenced using an $\mathrm{ABI}$ sequencer (Figure 3B). The genomic DNA extracted by all the three methods was found suitable for PCR sequencing. The sequencing profiles showed that the Modified Nucleospin Blood kit method depicted least noise followed by the Modified TianGen Kit method, whereas the phenolchloroform method successfully sequenced the gene fragment but was a bit noisy (Figure 3C).

\section{DISCUSSION}

Due to increasing concern for food safety, cow's milk can be used for population screening for disease diagnosing, eradicating genetic diseases and disease-resistance/susceptibility studies (Psifidi et al., 2010). In early studies, the phenol-chloroform method was generally used for DNA extraction from different kind of tissues, but it was not applicable for largescale studies because sufficient amounts of good quality DNA were not obtained from milk samples (Lipkin et al., 1993; Murphy et al., 1995). Recently, several studies have reported that milk somatic cells can be used as a source of DNA (Murphy et al., 2002; Mihuaiu et al., 2009; Psifidi et al., 2010), but the high quantity and quality genomic DNA isolation from milk is still a major concern. The present study demonstrated that compared to the classical phenolchloroform method, the Modified Nucleospin Blood kit method was a bit expensive but was found to be efficient and the best method to obtain highly intact DNA of improved quantity and purity, and that the Modified TianGen kit method was next to the Modified Nucleospin Blood kit method in terms of DNA quantity and quality and lower cost.

A $260 / 280 \mathrm{~nm}$ absorbance ratio greater than 1.80 is considered standard for genomic DNA and refers to pure. In the present study, a $260 / 280 \mathrm{~nm}$ ratio of $1.85 \pm 0.17$ shown by Modified Nucleospin Blood kit method was highly desirable for purified genomic DNA, free of protein contamination. The $260 / 280 \mathrm{~nm}$ ratio for the Modified TianGen kit method was also near the standard value $(1.75 \pm 0.21)$, whereas the ratio for the phenol-chloroform method was lower than the standard ratio $(1.64 \pm 0.22)$, which indicated that genomic DNA still contained some protein impurities. The $260 / 230 \mathrm{~nm}$ absorbance ratio (an indicator of reagent contamination) with the Modified Nucleospin Blood kit method was in the normal range, whereas that for the Modified TianGen kit and phenol-chloroform methods was considerably lower than the standard ratio. This indicated that the DNA extracted by the latter two methods was not completely purified and the DNA contained some chemical reagents.

Mihuaiu et al. (2009) reported that DNA of more than $50 \mathrm{ng} / \mu \mathrm{L}$ and 260/280 ratio of 1-2 is considered sufficient for PCR applications. On the basis of these criteria and the PCR product of $C D 4$, the DNA yield and integrity was the highest with the Modified Nucleospin Blood kit method, and the Modified TianGen kit method was better than the phenol-chloroform method. The DNA extracted by the phenol-chloroform method was lower and less intact, which showed that the DNA was prone to accidental losses. In a study by Psifidi et al. (2010), $5 \mu \mathrm{L}$ DNA extract were used for visualization by gel electrophoresis, whereas in the present study, only $3 \mu \mathrm{L}$ genomic DNA extract were used for gel electrophoresis resulting in brighter bands than the previous studies. Moreover, 5 and $2 \mu \mathrm{L}$ DNA extracts were used for 50 and 20 $\mu \mathrm{L}$ PCR volumes in studies by Amills et al. (1997) and Psifidi et al. (2010), respectively. In the present study, only $1 \mu \mathrm{L}$ genomic DNA was used for a $20-\mu \mathrm{L}$ PCR volume, which was success- 
fully amplified with brighter bands compared to the above mentioned studies. This showed that the DNA extracted in the present study was better both in terms of quantity and quality.

Among the three methods, the Modified Nucleospin Blood kit method was found to be the method of choice with least noise for PCR-sequencing. However, the Modified TianGen kit and phenol-chloroform methods were a bit noisy but were found suitable for routine genotype sequencing. The probable reason for the noise with the aforementioned two methods was their poor $260 / 230$ values which showed that the genomic DNA extracted by these two methods was not highly purified.

Genomic DNA extracted from milk somatic cells has potential application in studies of the molecular basis of mastitis susceptibility. After successful extraction of purified DNA from bovine milk, genes related to inflammatory diseases will be studied for their possible association with bovine mastitis susceptibility and milk production traits. Our previous studies on DNA hypermethylation in $C D 4$ promoter in bovine blood samples had shown suppression of the expression of CD4 gene (Wang et al., 2013). Since DNA methylation modification is tissue-, time- and environment-specific, the study of the variation in DNA methylation of CD4 promoter in bovine milk samples is warranted in future research. High quality and quantity DNA is required for DNA methylation testing (Eckhardt et al., 2006; Balic et al., 2009; Docherty et al., 2009). Therefore, the aforementioned methods for genomic DNA isolation from bovine milk were optimized, in which the Modified Nucleospin Blood kit method can be successfully used for further epigenetic studies.

Notably, the important modifications incorporated in the three DNA extraction methods that increased DNA yield and quality were first the milk pre-treatment with PBS. PBS was used to remove the soluble proteins to make DNA extraction easy. Second, it was noted that the $260 / 280 \mathrm{~nm}$ and $260 / 230 \mathrm{~nm}$ ratio of genomic DNA isolated by the Modified Nucleospin Blood kit method increased with the addition of a second washing step with ethanol containing buffer, and in the case of the phenol-chloroform method the ratio also increased with the addition of a second wash with pre-cooled absolute ethanol. In case of the two kits, it was also noted that the DNA quantity was improved by the addition of pre-heated TE and incubation for 5 to $10 \mathrm{~min}$ to ensure complete elution of the genomic DNA.

In summary, milk can be an animal friendly and routine source for high quality and quantity genomic DNA extraction in lactating dairy cattle. All the three methods can be used for DNA extraction depending on the priority of the user. When aiming the high quantity and high purity DNA, the Modified Nucleospin Blood kit should be used as the method of choice, and should also be used for sensitive molecular work such as deep sequencing and DNA methylation analysis. The Modified TianGen kit and phenol-chloroform methods can be used successfully for routine PCR and gene sequencing. The phenol-chloroform method should be preferred when DNA is to be extracted from a large number of milk samples for simple molecular studies such as PCR assay, as it is the most cost-effective of the three methods. The Modified TianGen kit method should be used in case greater efficiency is required for extracting DNA from a large number of milk samples.

\section{ACKNOWLEDGMENTS}

Research supported by the Fund for Basic Research from the Ministry of Education of the People's Republic of China (\#2011JS006), the Earmarked Fund for Modern Agro-industry Technology Research Center (CARS-37), National Natural Science Foundation in China Project 
(\#31272420 and \#31172191), Changjiang Scholar and Innovation Research Team in University (IRT1191) and Chinese National Key Project (\#2011BAD28B02). The authors are grateful to the staff of the China Agricultural University dairy farm for providing the milk samples.

\section{REFERENCES}

Agbagwa IO, Datta S, Patil PG, Singh P, et al. (2012). A protocol for high-quality genomic DNA extraction from legumes. Genet. Mol. Res. 11: 4632-4639.

Amills M, Francino O, Jansa M and Sanchez A (1997). Isolation of genomic DNA from milk samples by using Chelex resin. J. Dairy Res. 64: 231-238.

Balic M, Pichler M, Strutz J, Heitzer E, et al. (2009). High quality assessment of DNA methylation in archival tissues from colorectal cancer patients using quantitative high-resolution melting analysis. J. Mol. Diagn. 11: 102-108.

Biase FH, Franco MM, Goulart LR and Antunes RC (2002). Protocol for extraction of genomic DNA from swine solid tissues. Genet. Mol. Biol. 25: 313-315.

Cremonesi P, Castiglioni B, Malferrari G, Biunno I, et al. (2006). Technical note: Improved method for rapid DNA extraction of mastitis pathogens directly from milk. J. Dairy Sci. 89: 163-169.

D'Angelo F, Santillo A, Sevi A and Albenzio M (2007). Technical note: A simple salting-out method for DNA extraction from milk somatic cells: investigation into the goat CSN1S1 gene. J. Dairy Sci. 90: 3550-3552.

Docherty SJ, Davis OS, Haworth CM, Plomin R, et al. (2009). Bisulfite-based epityping on pooled genomic DNA provides an accurate estimate of average group DNA methylation. Epigenetics Chromatin. 2: 3.

Eckhardt F, Lewin J, Cortese R, Rakyan VK, et al. (2006). DNA methylation profiling of human chromosomes 6, 20 and 22. Nat. Genet. 38: 1378-1385.

Feligini M, Frati S, Curik VC and Brambilla A (2005). Caprine $\alpha_{\mathrm{s} 1}$-casein polymorphism: Characterization of A, B, E and F variants by means of various biochemical and molecular techniques. Food Tech. Biotechol. 43: 123-132.

Gao J, Hou RG, Zhang HQ, He JZ, et al. (2011). A novel DNA extraction and duplex polymerase chain reaction assay for the rapid detection of Prototheca zopfii genotype 2 in milk. Lett. Appl. Microbiol. 53: 278-282.

He Y, Chu Q, Ma P, Wang Y, et al. (2011). Association of bovine CD4 and STAT5b single nucleotide polymorphisms with somatic cell scores and milk production traits in Chinese Holsteins. J. Dairy Res. 1-8.

Hinrichs D, Stamer E, Junge W and Kalm E (2005). Genetic analyses of mastitis data using animal threshold models and genetic correlation with production traits. J. Dairy Sci. 88: 2260-2268.

Holmes CW and Wilson GF (1984). Milk Production from Pastures. Butterworths of New Zealand, Wellington.

Kehrli ME Jr and Shuster DE (1994). Factors affecting milk somatic cells and their role in health of the bovine mammary gland. J. Dairy Sci. 77: 619-627.

Lipkin E, Shalom A, Khatib H, Soller M, et al. (1993). Milk as a source of deoxyribonucleic acid and as a substrate for the polymerase chain reaction. J. Dairy Sci. 76: 2025-2032.

Mihuaiu R, Mihuaiu M, Orolan T, Dan SD, et al. (2009). DNA extraction methods used in leptins identification from buffalo milk. Bull. UASVM, Vet. Med. 66: 300-305.

Murphy MA, Sharifou MR and Moran C (1995). DNA from milk. Proceedings of the Australian Association of Anim. Breed. Genet. 11: 696 .

Murphy MA, Shariflou MR and Moran C (2002). High quality genomic DNA extraction from large milk samples. J. Dairy Res. 69: 645-649.

O’Grady J, Sedano-Balbas S, Maher M, Smith T, et al. (2008). Rapid real-time PCR detection of Listeria monocytogenes in enriched food samples based on the ssrA gene, a novel diagnostic target. Food Microbiol. 25: 75-84.

Pant SD, Schenkel FS, Leyva-Baca I, Sharma BS, et al. (2007). Identification of single nucleotide polymorphisms in bovine CARD15 and their associations with health and production traits in Canadian Holsteins. BMC Genomics 8: 421.

Psifidi A, Dovas CI and Banos G (2010). A comparison of six methods for genomic DNA extraction suitable for PCRbased genotyping applications using ovine milk samples. Mol. Cell Probes 24: 93-98.

SAS Institute Inc. (2002). SAS/STAT Users Guide. Release 6. 3rd edn. Cary.

Studer E, Schaeren W, Naskova J, Pfaeffli H, et al. (2008). A longitudinal field study to evaluate the diagnostic properties of a quantitative real-time polymerase chain reaction-based assay to detect Staphylococcus aureus in milk. J. Dairy Sci. 91: 1893-1902.

Wang XS, Zhang Y, He YH, Ma PP, et al. (2013). Aberrant promoter methylation of the CD4 gene in peripheral blood cells of mastitic dairy cows. Genet. Mol. Res. 12: 6228-6239.

Genetics and Molecular Research 13 (2): 3319-3328 (2014)

CFUNPEC-RP www.funpecrp.com.br 